\title{
Implementation and Outcomes of a Community-Based Pulmonary Rehabilitation Program in Rural Appalachia
}

\author{
Daniel Doyle \\ Cabin Creek Health System FQHC \\ Chaffee Tommarello \\ Cabin Creek Health System FQHC \\ Mike Broce \\ Charleston Area Medical Center Health Education and Research Institute \\ Mary Emmett \\ Charleston Area Medical Center Health Education and Research Institute \\ Cecil Pollard \\ West Virginia University
}

Follow this and additional works at: https://researchrepository.wvu.edu/ctsi

Part of the Medicine and Health Sciences Commons

\section{Digital Commons Citation}

Doyle, Daniel; Tommarello, Chaffee; Broce, Mike; Emmett, Mary; and Pollard, Cecil, "Implementation and Outcomes of a Community-Based Pulmonary Rehabilitation Program in Rural Appalachia" (2017). Clinical and Translational Science Institute. 588.

https://researchrepository.wvu.edu/ctsi/588

This Article is brought to you for free and open access by the Centers at The Research Repository @ WVU. It has been accepted for inclusion in Clinical and Translational Science Institute by an authorized administrator of The Research Repository @WVU. For more information, please contact ian.harmon@mail.wvu.edu. 


\title{
Implementation and Outcomes of a Community-Based Pulmonary Rehabilitation Program in Rural Appalachia
}

\author{
Daniel Doyle, MD; Chaffee Tommarello, BA; Mike Broce, BA; Mary Emmett, PhD; Cecil Pollard, MA
}

\begin{abstract}
Purpose: To report on the implementation and clinical outcomes of a community-based pulmonary rehabilitation program in rural Appalachia.

Methods: Three rural health centers and a large referral hospital worked together to establish pulmonary rehabilitation services based on AACVPR guidelines. Each site hired at least 1 respiratory therapist. To measure clinical outcomes, a retrospective medical record study compared pre- and post-program values for the modified Medical Research Council dyspnea level, 6-minute walk test $(6 \mathrm{MWT})$, negative inspiratory force (NIF), respiratory disease knowledge, St George Respiratory Questionnaire (SGRQ), BODE index (body mass index, airflow obstruction, dyspnea and exercise capacity), and smoking status. The percentages of persons completing the program and participating in maintenance exercise after the program were recorded.

Results: During the first 20 months of the program, 195 unduplicated persons with qualifying chronic lung diseases started the program. Of these, $111(57 \%)$ completed the program. Mean improvements for all 6 measures were highly significant $(P<$ $.001)$ and compared favorably with published results from hospital-based programs: dyspnea level, $-1.2 ; 6 \mathrm{MWT},+259 \mathrm{ft}$; NIF, $+11.3 \mathrm{~cm} \mathrm{H}_{2} \mathrm{O}$; knowledge test, +1.9; SGRQ, -6.2 ; BODE index, -1.1 . Of the 23 smokers, 5 quit by the end of the program. Conclusions: Community-based pulmonary rehabilitation in rural health centers is feasible and achieves clinical outcomes similar to programs in large hospitals and academic centers. Furthermore, the addition of respiratory therapists to these primary care teams provides important collateral benefits for the evidence-based care of patients with chronic lung diseases.
\end{abstract}

Key Words: community-based services $\bullet$ federally funded qualified community health center $\bullet$ primary care $\bullet$ pulmonary rehabilitation $\bullet$ rural

hronic obstructive pulmonary disease (COPD) is the third leading cause of death in the United States and the sixth leading cause in the world. ${ }^{1,2}$ COPD affects

\footnotetext{
Author Affiliations: Cabin Creek Health System FQHC, Dawes, West Virginia (Dr Doyle); New River Health System FQHC, Scarbro, West Virginia (Dr Doyle); West Virginia University Department of Family Medicine, Morgantown, West Virginia (Dr Doyle); Cabin Creek Health System FQHC, Dawes, West Virginia (Ms Tommarello); Charleston Area Medical Center Health Education and Research Institute, Charleston, West Virginia (Mr Broce and Dr Emmett); and Office of Health Services Research, West Virginia University School of Public Health, Morgantown, West Virginia (Mr Pollard).

All authors have read and approved the manuscript.

The authors declare no conflicts of interest.

This is an open-access article distributed under the terms of the Creative Commons Attribution-Non Commercial-No Derivatives License 4.0 (CCBYNC-ND), where it is permissible to download and share the work provided it is properly cited. The work cannot be changed in any way or used commercially without permission from the journal.

Correspondence: Daniel Doyle, MD, Cabin Creek Health System, 5722 Cabin Creek Rd, Dawes, WV 25054 (ddoyle@cchcwv.com).

Copyright (C) 2017 The Authors. Published by Wolters Kluwer Health, Inc. DOI: 10.1097/HCR.0000000000000247
}

15 million $(6 \%)$ of US adults and many more worldwide. ${ }^{2}$ Costs in lost productivity and medical services are high, with direct annual costs of $\$ 30$ billion in the United States and $€ 38$ billion for Europe. ${ }^{2}$ Pulmonary rehabilitation (PR) programs combine defined education modules and exercise training over a period of 12 weeks and 24 sessions. ${ }^{3}$ PR improves quality of life, exercise capacity, and dyspnea levels for persons with COPD of moderate severity or greater. ${ }^{4-7}$ PR also benefits persons with other types of chronic lung disease. ${ }^{8}$ Numerous expert guidelines recommend PR for persons with COPD and other chronic lung diseases., ${ }^{2,-11}$

Despite this evidence and these expert recommendations, PR is severely underutilized..$^{9,10}$ Fewer than $20 \%$ of persons with COPD enter and complete PR programs in the United States. ${ }^{12}$ There are many reasons for this unfortunate health care gap including poor reimbursement levels, lack of awareness by primary care providers, and lack of available programs in many communities. ${ }^{12}$ Access to programs is limited, especially in rural areas, due to geographic isolation and transportation barriers. This study describes the development and results of a PR program carried out by a network of rural primary care centers in the Appalachian region of North America.

\section{MATERIALS AND METHODS}

\section{PROJECT BACKGROUND AND HISTORY}

In 2012, a family foundation and a US Senator approached a federally qualified community health center (FQHC) in West Virginia and proposed the establishment of PR programs in multiple rural communities. This proposal grew out of the personal experience and commitment of the foundation directors. The leadership of the health center identified 3 rural health centers and an academic tertiary care center as clinical partners for this program. They also recruited 5 entities to provide the matching funds as required by the family foundation. The FQHC, a nonprofit corporation, served as the grantee and fiscal agent for this effort. In August 2013, the pooled funds became available and the Grace Anne Dorney Pulmonary Rehabilitation Project of West Virginia (GADPRP) began.

Three sites were invited to participate in the program, 2 FQHCs and 1 critical access rural hospital. All signed a memorandum of agreement to provide services according to the program model. That model followed the AACVPR guidelines for pulmonary rehabilitation, which includes staffing by a registered respiratory therapist, 12 weeks and 24 sessions of education and exercise, coverage of 8 core educational topics, assessment and attention to psychosocial and nutritional issues, encouragement of continued exercise (maintenance) after program completion, and ongoing program evaluation. ${ }^{3}$

Program startup at all 3 sites included creating space, recruitment and hiring of respiratory therapists and other staff, identifying supervising physicians, purchase of exercise 
equipment, purchase of educational materials, and preparation of policies. ${ }^{13}$ Administrative staff had to prepare budgets, arrange liability coverage, and quickly learn about billing codes and procedures. Before the first participants were enrolled, respiratory therapists and support staff from the 3 sites began meeting to agree on definitions, protocols, and evaluation procedures. An experienced respiratory therapist from the tertiary care hospital's PR program attended these meetings and had the therapists come to the hospital to learn PR procedures. With this support and preparation, the GADPRP began enrolling and conducting rehabilitation sessions with the first participants on November 1, 2013. This study was approved by the Charleston Area Medical Center Institutional Review Board as a retrospective medical records study and was exempted from obtaining signed informed consent.

\section{THE GRACE ANNE DORNEY PULMONARY REHABILITATION PROGRAM}

Persons were referred by primary care providers, community physicians, and pulmonologists. Persons with all qualifying chronic lung disease diagnoses were accepted including COPD, restrictive lung diseases, pneumoconiosis, asthma, cystic fibrosis, and pulmonary hypertension. Prior to beginning exercise, participants had a medical history review, medication review, chest x-ray, spirometry, electrocardiogram, and examination by a physician affiliated with the program. An individual treatment program and exercise prescription was completed collaboratively by the respiratory therapist and program physician.

Once the screening was completed, baseline clinical measures were obtained including a modified Medical Research Council (mMRC) dyspnea level, 6-minute walk test (6MWT), negative inspiratory force test (NIF), lung disease knowledge test, St George Respiratory Questionnaire (SGRQ), and BODE (body mass index, airflow obstruction, dyspnea and exercise capacity) index. Each patient then completed a 12 -week, 24-session program of graded exercise and education. Due to exacerbations, comorbidities, or other life problems, it often required longer than 12 weeks to complete all 24 sessions. At the time of program completion, the 6 baseline assessments including $\mathrm{mMRC}$, 6MWT, NIF, knowledge test, SGRQ, and BODE index were repeated. The program graduate was then invited and encouraged to attend a supervised maintenance exercise program weekly at the rehabilitation center for a nominal fee.

\section{DATA MANAGEMENT AND STATISTICAL ANALYSIS}

Measures of program activity and completion were recorded by each site throughout the program. On a quarterly basis, "snapshot" assessments were completed for the mutually exclusive categories of Active, Approved/on-hold, Graduated, and Discharged. The categories Graduated and Discharged were reset to zero at the end of each calendar year.

Business associate agreements existed between the 3 sites and the research institute of the tertiary care hospital partner. For each participant, demographic data, vital signs, pre- and post-clinical measures were entered into the clinical care coordination software (CAPGate). CAPGate.org is a HIPAA-compliant secure Internet Web site maintained and supported by Partners in Health Network of Southern West Virginia. ${ }^{14}$ CAPGate allows for the integrated tracking of primary care, care coordinator interventions, and hospital utilization data. For the research protocol these records were de-identified.

All analyses were performed using SPSS version 19.0 (IBM, Armonk, NY). Descriptive statistics are expressed in terms of frequencies, percentages, or means ( 1 standard deviation). Paired samples $t$ tests were used to compare preand post-PR physiologic and psycho-educational measures. A $P$ value $\leq .05$ was considered significant. Where deemed appropriate, possible variable interactions and measures of minimal important difference were used to evaluate outcomes.

\section{RESULTS}

\section{PROGRAM PARTICIPATION AND GRADUATION RATES}

There were a total of 195 unduplicated persons who enrolled in the GADPRP between November 1, 2013, and June 30, 2015. Of these, 111 completed the program (graduated) for an overall completion rate of $57 \%$. Reasons for dropout included exacerbations of pulmonary illness, complications of other illnesses, loss of mobility, expense, transportation, and death.

Graduation rates varied among the 3 sites with rates of $51 \%, 70 \%$, and $48 \%$ at sites 1,2 , and 3 , respectively $(P<$ $.015)$. Possible reasons for this difference included variation in patient selection, transportation barriers, staffing ratios, staff personalities and motivation, and respiratory therapist job descriptions and responsibilities within their respective institutions.

\section{CLINICAL OUTCOMES FOR GRADUATES}

Table 1 shows clinical outcomes for the 111 program graduates. There were significant improvements in all 6 outcome measures $(P<.001)$. These included 6MWT, $+259 \mathrm{ft}$; BODE index, -1.1 ; mMRC dyspnea level, -1.2; $\mathrm{NIF},+10.5 \mathrm{~mm} \mathrm{Hg}$; SGRQ, -6.2 ; and knowledge score, +1.9 . Knowledge scores and NIF data were not used from site 3 because, during the evaluation, the methods were found to be invalid. Five of the 23 smokers quit during the

\section{Table 1}

Clinical Outcomes for Patients Who Completed PR Program $(n=111)$

\begin{tabular}{lccccc}
\hline & Pre-PR & Post-PR & Mean Change \pm SD & 95\% CI & P Value \\
\hline Dyspnea level, mMRC & 3 & 1.8 & $-1.2 \pm 1.1$ & -1.39 to -1.01 & $<.001$ \\
6-min walk test, ft & 760 & 1019 & $259 \pm 238.2$ & 214 to 304.44 & $<.001$ \\
NIF, cm Ha $\mathrm{O}^{\mathrm{a}}$ & 78.2 & 88.7 & $10.5 \pm 19.5$ & 5.89 to 15.15 & $<.001$ \\
Knowledge test score $^{\mathrm{a}}$ & 15.8 & 17.7 & $1.9 \pm 2.4$ & 1.33 to 2.49 & $<.001$ \\
SGRQ & 54.6 & 48.4 & $-6.2 \pm 14.4$ & -8.88 to -3.46 & $<.001$ \\
BODE index & 3.4 & 2.3 & $-1.1 \pm 1.1$ & -1.29 to -0.86 & $<.001$ \\
\hline
\end{tabular}

Abbreviations: BODE, body mass index, airflow obstruction, dyspnea and exercise capacity; mMRC, modified Medical Research Council; NIF, negative inspiratory force test; PR, pulmonary rehabilitation; SGRQ, St George Respiratory Questionnaire; SD, standard deviation.

${ }^{a} \mathrm{NIF}$ and knowledge test data were from sites 1 and 2 only because measurement technique was not valid at site 3 for these measures. 


\begin{tabular}{|c|c|c|c|c|c|}
\hline & Study & $\mathbf{n}$ & $\Delta 6 \mathrm{MWT}$ & $\Delta$ SGRQ & $\triangle \mathrm{BODE}$ \\
\hline Ries et al ${ }^{4}$ & NETT & 1218 & $76 \mathrm{ft}$ & -3.5 & - \\
\hline Puhan et al ${ }^{15}$ & CDSR & 432 & $253 \mathrm{ft}$ & -9.88 & - \\
\hline Major et $\mathrm{al}^{6}$ & Cincinnati veterans study & 78 & $246 \mathrm{ft}$ & -9.5 & -1.24 \\
\hline McCarthy et $\mathrm{al}^{7}$ & CDSR & 3822 & $144 \mathrm{ft}$ & -6.89 & - \\
\hline Doyle et $\mathrm{al}^{\mathrm{a}}$ & GADPRP study & 111 & $259 \mathrm{ft}$ & -6.2 & -1.1 \\
\hline
\end{tabular}

Abbreviations: $\triangle B O D E$, change in body mass index, airflow obstruction, dyspnea and exercise capacity index; CDSR, Cochrane Database of Systematic Review; $\triangle 6 M W T$, change in 6-minute walk test; NETT, National Emphysema Treatment Trial; $\triangle \mathrm{SGRQ}$, change in St George Respiratory Questionnaire; GADPRP, Grace Anne Dorney Pulmonary Rehabilitation Project of West Virginia. aStudy reported in this article.

program. The mean improvement for the 6MWT was 259 $\mathrm{ft}(P<.001)$. For this measure, 2 persons were unable to complete a post-6MWT; 3 showed no change (within 40 $\mathrm{ft}$ of pre-test); 11 had a decrease in distance walked; 95 improved by $>40 \mathrm{ft}$; and $84(76 \%)$ exceeded a minimal important difference of $85 \mathrm{ft}^{15}$

Table 2 compares the results from our study with results of the same assessments from 4 major studies. The outcomes from our study compare favorably with those published outcomes obtained in PR programs in hospital and academic center settings. Because of differences in patient groups and intervention methods, we did not attempt statistical comparisons with other studies.

\section{EXERCISE MAINTENANCE AFTER GRADUATION}

National guidelines stress the importance of continuing regular exercise after completion of a PR program in order for benefits to be maintained. ${ }^{3}$ Graduates of GADPRP had the opportunity to return to the training site several times per week for exercise in a familiar environment with staff present. Among the 111 graduates of this program, $40(36 \%)$ have returned for exercise at their program site at least once. Some graduates choose to exercise at home or in other venues. All 3 sites offered times for graduates to continue their exercise program while being monitored by staff.

\section{DISCUSSION}

This evaluation was undertaken with 3 main questions for consideration: (1) Is rural office-based PR feasible? (2) What percentages of persons are able to complete a 12-week, 24-session program? (3) Are clinical outcomes equal to those obtained in hospital-based or academic center settings?

This study demonstrated that it is definitely feasible to deliver guideline-consistent PR in rural primary care settings. Furthermore, all 3 sites are strong and growing 30 months after starting. Two more affiliated PR sites have recently opened in FQHCs in 2 additional rural WV counties. This report provides an experience-based measure of typical graduation rates for this type of program, $57 \%$ with a range of $48 \%$ to $70 \%$. When the added benefits of easier access, post-program continuity of care, and reduced transportation costs are factored in, the case for expanded rural PR services is very strong.

The benefits of PR for quality-of-life, dyspnea levels, and exercise capacity have long been documented. ${ }^{4-7}$ More recently, evidence is growing regarding cost savings from PR by reduced hospitalization after exacerbations and overall. ${ }^{5,16,17}$ Hopefully, this evidence will convince payers, including state Medicaid programs, to begin paying for PR on a regular basis. An important theme of contemporary chronic disease care is education and activation of patients to do their own self-care. It is hard to imagine a program that better embodies this approach than PR with its handson support for regular physical activity and its defined set of education modules.

During this study, we observed important collateral benefits of having respiratory therapists in primary care settings. They improved the frequency and quality of indicated pulmonary function testing. They improved provider skill and confidence in interpreting spirometry and improved application to clinical care. They can support providers in such tasks as oxygen certification and recertification, sleep studies, orders and education for continuous positive airway pressure, asthma action plans, and improved self-care skills for all patients with chronic lung diseases, not just patients who choose PR. These collateral benefits are so great that this project could be viewed more broadly as "bringing respiratory therapy services to primary care" rather than limited to pulmonary rehabilitation.

This study has several limitations. Persons with all types of chronic lung disease were included in this study, which limits comparison to studies of COPD only. Data regarding benefits to persons who partially completed the program were not available. One site had knowledge test and NIF results that could not be included because of faulty measurement techniques. Finally, a formal evaluation of patient satisfaction was not carried out at all sites.

\section{CONCLUSIONS}

A guideline-based pulmonary rehabilitation program can be successfully conducted in rural primary care settings with outcomes similar to those reported from large hospitals and referral centers. Adding respiratory therapists to the health care team has collateral benefits including improved frequency and quality of indicated pulmonary function testing, improved knowledge and use of guidelines for chronic lung diseases, and improved patient education for chronic lung diseases.

\section{ACKNOWLEDGMENTS}

The authors acknowledge the contributions to this study by the following persons: Len Picha, William Carte, Amanda Jones, Susie Criss, Craig Robinson, Amber Crist, and Philip Galapon. Research support for this study was provided by grants from the West Virginia Clinical and Translational Sciences Institute (National Institute of General Medical Sciences, U54GM104942), the Claude Worthington Benedum Foundation, and the Dorney-Koppel Foundation. This study was conducted under the auspices of the West Virginia Practice Based Research Network. 


\section{REFERENCES}

1. MMWR. Chronic obstructive pulmonary disease among adultsUnited States, 2011. MMWR. 2012;61:938-943.

2. Global Initiative for Chronic Obstructive Lung Disease. Global Strategy for the Diagnosis, Management, and Prevention of Chronic Obstructive Lung Disease. http://goldcopd.org/global-strategydiagnosis-management-prevention-copd-2016/. Updated 2016. Accessed June 1, 2016.

3. American Association of Cardiovascular and Pulmonary Rehabilitation. Guidelines for Pulmonary Rehabilitation Programs. 4th ed. Champaign IL: Human Kinetics; 2011.

4. Ries AL, Make BJ, Lee SM, et al. The effects of pulmonary rehabilitation in the national emphysema treatment trial. Chest. 2005; 128:3799-3809.

5. Puhan M, Gimeno-Santos E, Scharplatz M, Troosters T, Walters $\mathrm{EH}$, Steurer J. Pulmonary rehabilitation following exacerbations of chronic obstructive pulmonary disease. Cochrane Database Syst Rev. 2011;1(10):CD005305.

6. Major S, Moreno M, Shelton J, Panos R. Veterans with chronic obstructive pulmonary disease achieve clinically relevant improvements in respiratory health after pulmonary rehabilitation. J Cardiopulm Rehabil Prev. 2014;34:420-429.

7. McCarthy B, Casey D, Devane D, Murphy K, Murphy E, Lacasse Y. Pulmonary rehabilitation for chronic obstructive pulmonary disease. Cochrane Database Syst Rev. 2015;(2):CD003793. doi:10.1002/14651858.CD003793.pub3.

8. Rochester CL, Fairburn C, Crouch RH. Pulmonary rehabilitation for respiratory disorders other than chronic obstructive pulmonary disease. Clin Chest Med. 2014;35:369-389.

9. Rochester CL, Vogiatzis I, Holland AE, et al. An official American Thoracic Society/European Respiratory Society policy statement: enhancing implementation, use, and delivery of pulmonary rehabilitation. Am J Respir Crit Care Med. 2015;192:1373-1386.

10. Ries AL, Bauldoff G, Carlin B, et al. Pulmonary rehabilitation: Joint ACCP/AACVPR Evidence-Based Clinical Practice Guidelines. Chest. 2007;131(5, suppl):4S-42S.

11. National Institute for Health and Clinical Excellence (NICE). Chronic Obstructive Pulmonary Disease. Management of Chronic Obstructive Pulmonary Disease in Adults in Primary and Secondary Care (Partial Update). NICE Clinical Guideline 101. London, England: National Institute for Health and Clinical Excellence; 2010.

12. Barr RG, Celli BR, Martinez FJ, et al. Physician and patient perceptions in COPD: The COPD Resource Network Needs Assessment Survey. Am J Med. 2005;118(12):1415.e9-1415.e17.

13. Jenkins S, Hill K, Cecins NM. State of the art: how to set up a pulmonary rehabilitation program. Respirology. 2010;15: 1157-1173.

14. Partners in Health Network. CAPGate User Manual. Charleston, WV: Partners in Health Network; 2015. https://www.capgate.org/ aboutus/user_manual. Accessed September 23, 2016.

15. Puhan MA, Chandra D, Mosenifar Z, et al. The minimal important difference of exercise tests in severe COPD. Eur Respir J. 2011;37:784-790.

16. Nguyen H, Harrington A, Liu I, Lee J, Gould M. Impact of pulmonary rehabilitation on hospitalizations for chronic obstructive pulmonary disease among members of an integrated health care system. J Cardiopulm Rehabil Prev. 2015;35:356-366.

17. Gillespie P, O'Shea E, Casey D, et al. The cost-effectiveness of a structured education pulmonary rehabilitation programme for chronic obstructive pulmonary disease in primary care: the PRINCE cluster randomised trial. BMJ Open. 2013;3(11):e003479. 